Derecho y Realidad

Núm. 22 • II semestre de 2013

Facultad de Derecho y Ciencias Sociales, UPTC

ISSN: 1692-3936

\title{
Ética y política en Colombia Martí, ese misterio que nos puede acompañar
}

Ethics and politics in Colombia

Marti, that mystery which can accompany us

Héctor Arenas Amorocho*

Resumen

El 3 de enero de 1880, José Martí llegó a Nueva York desde su destierro en España, que sucedió a su presidio en Cuba. Llegó a vivir en lo que él llamo «el pueblo más libre y grandioso de la tierra» y se declaró contento de habitar en un país «donde todo el mundo parece su propio amo». Venía con la herida abierta de la isla aún sometida a la aristocracia peninsular.

Palabras clave

José Martí, revolución de la dignidad, Cuba, Estados Unidos.

* Investigador colombiano independiente. 


\section{Abstract}

On January 3, 1880, José Martí came to New York from his exile in Spain, after his imprisonment in Cuba. He came to live in what he called «the most free and great people of the earth» and declared himself happy to live in a country "where everyone seems to be his own master». He came with the open wound from the island still under peninsular aristocracy.

\section{Key words}

José Martí, revolution of dignity, Cuba, United States. 
Derecho \& Realidad

\section{Introducción}

El 8 de enero de 1881, Martí viajó a Venezuela "la cuna del continente libre" y al despedirse de este breve y decisivo viaje hacia el significado profundo de Bolívar, el 27 de julio de 1881, escribió una carta a su amigo editor Teodoro de Aldrey, y en uno de sus apartes señaló: "cuando se tienen los ojos fijos en lo alto, ni zarzas ni guijarros distraen al viajador en su camino: los ideales enérgicos y las consagraciones fervientes no se merman en un ánimo sincero por las contrariedades de la vida. De América soy hijo: a ella me debo. Y de la América, a cuya revelación, sacudimiento y fundación me consagro, esta es la cuna; ni hay para labios dulces copa amarga; ni el áspid muerde en pechos varoniles; ni de su cuna reniegan hijos fieles. Denme Venezuela en que servirla: ella tiene en mí un hijo”.

Martí regresó a los Estados Unidos e inició entonces, desde las entrañas de la naciente potencia, una asombrosa labor periodística de casi quince años, en la que comunicó su aguda observación y la evolución de su pensamiento sobre los Estados Unidos y sobre nuestra América (como él llamó a América Latina y el Caribe). Un territorio y una geografía entrelazados, que en el comienzo del siglo XXI se han convertido en espacios decisivos del mundo. El uno, por hospedar la dirección planetaria de un modo de vida que se ha revelado insostenible y cuya hegemonía, hasta ahora indiscutida, declina y se resquebraja en forma incontenible a raíz de la irremediable visibilidad de sus oprobiosos métodos y sus desastrosos resultados, y por su farragoso huir hacia delante fundado en el expediente militar como primordial sostén de su dominio.

La otra, Nuestra América, por convertirse en fuente inesperada de sorprendente creación social y política en un mundo inmovilizado en el vértigo autodestructivo, que asciende y alberga -justo en la temible vecindad del imperio- la rebeldía "hecha de cordura y cólera, razón y hambre, honor y reflexión”. Indo Afro Latinoamérica es también tierra de asombrosos y esperanzadores florecimientos de humanidad y conciencia que brotan de la semilla de la virtud hermanada con la política.

Cuando Martí llego a Nueva York, los Estados Unidos, con credo de libertad, protección a sus pujantes industrias, comercio creciente, un abismo cada vez más profundo entre la ética y la política, y expansión militar por la cuenca del Caribe - para asegurar también el que, desde comienzos del siglo IXX, fue considerado estratégico control del paso interoceánico en Panamá (Díaz, 1997)-, avanzaban raudamente en el desplazamiento de la Gran Bretaña en el dominio sobre el Sur de América.

Martí consagró entonces la plenitud de sus energías a dos tareas de una sola unidad esencial: por una parte esclarecer con sus escritos y el fuego de su palabra, los 
diferentes sentido de la revolución de la dignidad y el decoro que iluminaban su insomne batallar en pos de una República moral en América, con todos y para el bien de $\operatorname{todos}^{1} \mathrm{y}$, por otra parte, se dedico -él, que amó la paz verdadera como pocos seres quizás la han amado- a culminar los preparativos para librar, en compañía de los "hombres rebeldes y cordiales", la guerra que quería breve, para "sacar a tiempo la patria interrumpida de la nación que la ahoga y la corrompe, y le bebe el alma y le clava los vuelos”.

En la primera tarea, se ocupó en fundar la libertad, previendo y explicando las múltiples facetas del poder moral que tendría que guiar en cada detalle la obra colectiva, y sin el cual la independencia no tendría sentido, pues no se avanzaría entonces en la tarea sagrada de transmutar la fiera en ser humano, lo turbio y la tiniebla, en luz. Así , observó, estudió, meditó y creó en la escritura y la tribuna para librar a su pueblo del mal que contempló en los Estados Unidos: donde del acumulamiento mismo del hombre vienen soledad y abandono espantosos ... pueblo de niños educados en la regata funesta por la riqueza en la que sin sueño y sin día de fiesta forcejea la nación; y para librar también a su nación, en el inevitable momento del fuego emancipador, de las "fieras querellas que mueven en los pueblos nacientes los odios triunfantes y los desordenados apetitos".

Martí contempló el germen de la descomposición:

En la médula, en la médula está el vicio, en que la vida no va teniendo en esta tierra más objeto que el amontonamiento de la fortuna, en que el poder de votar reside en los que no tienen la capacidad de votar"; y consagró entonces sus energías a revelar ese otro sentido más pleno de la vida y la democracia que palpita desde las tradiciones comunitarias ancestrales en venas de nuestra América y pugna por ser expresado y vuelto a la guía de los devenires colectivos.

Abordó también las claves de la siembra de conciencia y elevación del espíritu para situarlo en capacidad de participar activamente en la fundación diaria de la republica: da miedo ver cómo crece esta alma interesada; odiadora y dura. ¿Que se derriben templos? Aquellos donde se predique el odio, o la intolerancia, vénganse abajo en buena hora; pero ¿templos? Ahora se necesitan más que nunca, templos de amor y humanidad que desaten todo lo que hay en el hombre de generoso y sujeten todo lo que hay en él, de crudo y vil.

\footnotetext{
1 Ver la obra de Paúl Estrade José Martí, los fundamentos de la democracia en Latinoamérica, y el excelente prefacio de Roberto Fernández Retamar. De especial valor el contrapunto sobre la concepción martiana de democracia con la democracia racista y con esclavitud admirada por Tocqueville en su famosa obra sobre los Estados Unidos.
} 
No se dejó deslumbrar por los espejismos del espectacular desarrollo que experimentaba Norteamérica y anticipó a donde conducirían las reglas de juego del ritmo delirante y soberbio, y la feroz competencia:

En los ateneos se habla mucho de progresos insignes, y en los editoriales de los diarios; pero no se ve que se está haciendo en casi todas partes el pan nacional con levadura de tigres. Esto sobre todo es peligroso en países donde, como en este, el tigre manda. Así las republicas van a los tiranos. Quien no ayuda a levantar el espíritu de la masa ignorante y enorme, renuncia voluntariamente a su libertad. / Nación que no cuida de ennoblecer a sus masas, se cría para los chacales. / Ha echado por caminos la existencia moderna, en que la serenidad de ánimo, la claridad de lo interior y la vida legitima van siendo imposibles.

En la segunda tarea, su colosal esfuerzo se concentró en forjar la imprescindible reunión de todos los cubanos y en mostrar como las normales ambiciones y las naturales diferencias que existían entre los múltiples pareceres que participaban en la causa de la liberación, no podían hacerse prevalecer en forma alguna por sobre la unidad exigida por la urgencia suprema de la independencia absoluta de Cuba:

Los enemigos de la libertad de un pueblo, no son tanto los forasteros que la oprimen, como la timidez y vanidad de sus propios hijos. El oficio de los libertadores no es devorarse entre sí, y codearse unos a otros ante la muchedumbre, y mirar hosco al que les cierra el paso, y derretirlo con el fuego de los ojos, y echarlo atrás a uñadas y mordeduras y ponerse adelante, a donde todo el mundo lo vea, como la odalisca que llegó por fin a atraer la mirada del sultán: el oficio de los libertadores no es alquilar elocuencias, pagar plumas, adular a satélites, acaudillar bandos, asalariar hipócritas, encubrir espías, costear vicios, pensionar desvergüenzas; ni ir de oído en oído cosquilleando el patriotismo, mendigando el cumplimiento del deber...

La independencia real formaba parte de un designio más profundo, que él entrevió como objetivo para consolidar en tiempos venideros, y ha llegado hasta nuestros días: "Es un mundo lo que estamos equilibrando: no son solo dos islas las que vamos a libertar".

Acercarse hoy a la fuente prístina de los escritos de Martí con toda la reflexión creadora que exigen, y participar entonces en la inevitable responsabilidad de compartir los fulgores germinativos de su pensamiento y su parábola vital, puede aportar mucho y en lo decisivo, en el vital desafío ético que enfrenta el pueblo de pueblos que es Colombia. Estremecerse con la asombrosa vigencia de sus ideas y vislumbrar su sobrenatural fuerza de dignidad puede potenciar en forma inimaginada 
las energías consagradas a la sagrada responsabilidad de alentar el espacio político de unidad de la diversidad alterno ${ }^{2}$ a la criminal arbitrariedad y el hedor insoportable de la podredumbre hasta ahora imperantes.

Abrevar en el pensamiento de Martí es hallar luz de nuestra América y aire puro en un territorio ensombrecido por los miasmas de la más bárbara y nauseabunda corrupción. A los estragos causados por tres siglos de embustes y crueldad extrema de historia colonial, se han sumado los efectos monstruosos de los descomunales presupuestos para la guerra, la mentira organizada y el odio inoculado, que han convergido en una Colombia clasificada por la alianza atlántica como escenario geoestratégico en una Latinoamérica que se sale del control hegemónico. La yunta con la ambición y la codicia nacionales en la lucrativa profanación de la vida, los territorios y las plantas sagradas, desataron una máquina de horror que arroja sin pausa un caudal inimaginable de sufrimiento.

Desmontar esta tremenda dinámica de ruindad y degradación de la bondad natural, exige una colosal labor reunida en torno impostergable tarea de sustraernos a la mordedura que nos aferra y desangra. Aliviar, curar y revivir allí donde tanto daño se ha infringido, donde se ha herido y se ha lastimado y se ha matado el tejido más intimo y delicado que nos conforma como comunidad, es parte de la sagrada labor común $^{3}$. La fuerza visionaria y ensoñadora de Martí puede ayudar a esclarecer y alentar la acción colectiva capaz de cesar el curso de horror fratricida.

Las tradiciones ancestrales que sobreviven en Colombia, que son parte esencial de nuestras raíces ignoradas, y que han preservado -pese a la bestial embestida que ahora recrudece su ensañamiento con fuerza devastadora ${ }^{4}$ - vitales armonías y sostenido relaciones de respeto y afecto inimaginables con la madre tierra, resguardan aún un caudal ético que si silenciado, no ha sido borrado en nuestra manera de sentir: su infinita humildad desprovista de toda sombra de ego o de soberbia; su natural tendencia a valorar la palabra como instancia sagrada y creadora, y a unir lo que se expresa con lo que se piensa y siente, y lo que se dice con lo que se hace, dimensión crucial hoy

2 www.polodemocratico.net

3 Sobre el carácter sistemático y los alcances monstruosos del proceso de exterminio, ver Vértigo en el Jardín del mal de José Gutiérrez y los testimonios de Javier Giraldo y Gustavo Petro en www.javiergiraldo.org y http:/gustavopetro.blogspot.com/, y los libros Prohibido Olvidar de Maureen Amaya y Gustavo Petro Sobre la asombrosa resistencia de la vida y la cultura; ver, por ejemplo, todo lo relacionado con el movimiento participativo de víctimas orientado a erradicar estrategias y modelos criminales practicados por el Estado: www.movimientodevictimas.org; lo relacionado con las comunidades de paz y pueblos indígenas www.cdpsanjose.org, www.onic.org, www.nasaacin.net; con la paz www.peacebrigades.org; con las mujeres en la defensa de los derechos humanos, por la paz y contra la guerra www.nodo50.org/asipazcol/mujeres.htm; con la defensa de los derechos fundamentales y los derechos de los pueblos: www.colectivodeabogados.org, etc.

4 Más de un millón de hectáreas en santuarios naturales fumigadas con diversos tóxicos y millones de seres humanos de culturas nativas, afros y rurales, forzados al destierro. 
que los significados originales de las palabras han sido saqueados metódicamente y se hace una cosa mientras se dice otra; "hacer, es la mejor manera de decir" y "Pongo más atención a mis obras que a mis discursos", decía Martí. También la sensibilidad, el respeto y el amor sin límites hacia las diversas expresiones de la vida; los saberes del cuidado de sí y su capacidad de leer en el libro de la naturaleza: "El bosque vuelve al hombre a la razón y a la fe, y es la juventud perpetua. El bosque alegra, como una buena acción. La naturaleza cura, inspira, fortalece y prepara para la virtud al hombre, el hombre no se halla completo, ni se revela a sí mismo, ni ve lo invisible, sino en su íntima relación con la naturaleza".

No fue accidental en los anhelos de Martí la comprensión de lo que significaban los pueblos ancestrales de nuestra América:

No más que pueblos en cierne, no más que pueblos en bulbo eran aquellos en que con maña sutil de viejos vividores se entró el conquistador valiente, y descargó su poderosa herrajería, lo cual fue una desdicha histórica y un crimen natural. El tallo esbelto debió dejarse erguido, para que pudiera verse luego en toda su hermosura la obra entera y florecida de la Naturaleza. ¡Robaron los conquistadores una página al Universo!

Interrumpida por la conquista, la obra natural y majestuosa de la civilización americana, se creó con el advenimiento de los europeos un pueblo extraño, no español porque la savia nueva rechaza el cuerpo viejo; no indígena, porque se ha sufrido la injerencia de una civilización devastadora... de aquella absorción cruenta algo quedó de la vencida raza: el espíritu, que resiste siempre al acero, al hierro y al fuego... Así nosotros, con todo el raquitismo de un infante malherido en la cuna, tenemos toda la fogosidad generosa, inquietud valiente, y bravo vuelo de una raza original, fiera y artística. Toda obra nuestra, de nuestra América robusta, tendrá, pues, inevitablemente el sello de la civilización conquistadora; pero la mejorará, adelantará y asombrará con la energía y creador empuje de un pueblo en esencia distinto, superior en nobles ambiciones, y si herido, no muerto. ¡Ya revive!

Pero, regresando a la invitación a la lectura meditada de su obra periodística en los Estados Unidos, entre 1881 y 1892 (Fernández \& Rodríguez, 2003), y los artículos del periódico Patria (Bueno \& De la Torriente, s.f.) por el fundado en 1892 e íntegramente dedicado a la tarea emancipadora; los propósitos de este último hablan por sí mismos:

mantener la amistad entrañable que une, y debe unir, a las agrupaciones independientes entre sí, y a los hombres buenos y útiles de todas las procedencias, que persistan en el sacrificio de la emancipación, o se inicien 
sinceramente en él; a explicar y fijar las fuerzas vivas y reales del país, y sus gérmenes de composición y descomposición, a fin de que el conocimiento de nuestras deficiencias y errores, y de nuestros peligros, asegure la obra a que no bastaría la fe romántica y desordenada de nuestro patriotismo; y para fomentar y proclamar la virtud donde quiera que se la encuentre. Para juntar y amar, y para vivir en la pasión de la verdad nace este periódico.

En Colombia, la brega por la unidad emancipadora y por la verdad y la justicia aparece, a veces, con dimensiones de infranqueable cordillera. La pérfida industria de la amnesia ha estampado en nuestras mentes una historia que no se corresponde con nuestro pasado, impide comprender las raíces de nuestro monstruoso presente y descifrar el no futuro que se nos pretende imponer. Esa industria ha aislado con silencio o tapado con basura la memoria de quienes consagraron su vida a labrar una república con decoro en la que no faltase el pan y la cultura compartidos.

Al mismo tiempo, esa factoría de vacíos y falsedades ha exaltado una historia oficial en la que abundan los recuerdos grandilocuentes de quienes percibieron las coimas arrojadas por núcleos exógenos a cambio de entregar los territorios y riquezas comunes, y se plegaron a la persecución y aniquilación sistemática y masiva de los liderazgos y las multitudes no funcionales al orden hegemónico, mientras acataron imponer las reglas de juego que han sacrificado sin piedad todo lo vivo: niñez, jóvenes, mujeres, ancianos, comunidades, tierra, naturaleza, palabra de verdad, artes...

En 1943, Jorge Eliécer Gaitán en una entrevista para el diario El Siglo ya se refería así a una atmósfera en la que el ejercicio de la virtud no solo no favorecía, sino que era un obstáculo para asumir tareas de responsabilidad colectiva:

Uno de los problemas más inquietantes del país, a mi modo de ver, reside precisamente en la absoluta ausencia de estimulo de las virtudes humanas de la juventud, que parece ser doloroso patrimonio de la presente hora colombiana. Tanto más alarmante cuanto que a nadie alarma. El hombre no obra sin motivos, y cuanto faltan los generosos y elevados, se moverá por los exiguos y pequeños.

Las empresas de comunicación televisiva, en especial, y una parte no despreciable de la educación, se han encargado cada día y cada noche de esconder las claves luminosas de la vida y esclavizarnos en el modelo autodestructivo. Se ha atrofiado la capacidad de comprensión y reacción ante las imposiciones, los valores y la modulación del deseo que nos condenan a la miseria material y espiritual, y nos sumen en la feroz confrontación. Se ciega la posibilidad de ver los viles dispositivos de fabricación de monstruos, los mecanismos que potencian la fiera que nos habita, y se anestesia nuestra capacidad de actuar conjuntamente para impedir su fatal funcionamiento. 
Derecho y Realidad

Desde la mayor parte de la televisión se inocula un falso patriotismo de fútbol y latitas que sacrifica y mutila cuerpos por dividendos que llaman "Patria", mientras entrena en el desprecio a la vida y el odio a la diferencia. Se incomunica y se divide intimidando, sobornando, cooptando e insuflando desconfianza. Se enseña a despreciar lo más valioso, propalando el valor del comportamiento rastrero para alcanzar el "éxito". La imagen, el afeite, la encuesta prevalecen en las decisiones sobre los principios y el sencillo procurar hacer bien lo que se hace. Se normaliza el atropello y se machacan en los cerebros y los cuerpos sin piedad las prácticas y valores del demencial egoísmo.

Con un acumulado histórico de esta naturaleza, que ha funcionado al servicio del acatamiento ignorante, resignado, acomodaticio o incluso furibundo del orden monstruoso y de la cultura que regula desastrosamente -por no conocer- el cuidado de sí y la dimensión del amor, no es difícil entonces encontrar un peso considerable de la incredulidad y de comportamientos funcionales al desastre vigente. No interesa, o no se comprende, o no se sabe como participar masivamente en la imprescindible revolución ética capaz de disipar las fuentes del miedo y la agresión, y se ignora como desobedecer o no colaborar con el curso de horror y con una política no solo alejada de la ética, sino que funciona en contravía de la ética.

El 19 de enero de 1883 escribió Martí acerca de las elecciones en Estados Unidos:

Ayudaban los políticos a los ricos, y los ricos a los políticos. Los poderosos del mercado vaciaban sus mejores bolsas para cosechar votos, ganarse empleados, y favorecer ardides en la hora de las elecciones, a trueque de que los electos favoreciesen luego con sus votos los planes en que cifraban mayores esperanzas de fortuna los ricos mercaderes.

Que ahora las más cuantiosas riquezas estén en las finanzas internacionales engordadas en delirantes y fatídicos juegos especulativos, en los más lucrativos tráficos: drogas, armas, seres humanos-, en los apropiadores de los últimos yacimientos de energías fósiles articulados a los que impulsan el aberrante proceso de erradicar los cultivos de alimentos de las comunidades sustituyéndolos por agrocombustibles, y en los propietarios monopólicos y complotados de la privatizada e insostenible economía del despilfarro, y que, junto a la compra de los votos y los fraudes, en Colombia se haya utilizado la masacre, el narcodinero y los métodos del espanto para fabricar resultados electorales, no varía la esencia calamitosa del asunto, sino que revela a donde conduce el germen de descomposición que vio Martí. Que aún ahora se pretenda dar continuidad a esta forma abyecta e infeliz de interpretar la comunidad y su devenir, aparentando ante la galería erradicar una ejecutoria monstruosa que en realidad se ha pretendido legalizar, revela el ánimo nihilista que gobierna la empresa. 
Pero -imposible no decirlo con Martí- para nuestra fortuna:

No están en el fondo de los barriles de cerveza, ni en la voluntad ruin de unos cuantos vagabundos o menesterosos mercadeables, las leyes venideras de un pueblo fuerte y bueno. Se sienta mal el que se sienta sobre hombros pagados; porque acabado el goce del dinero, para servir a nuevo señor, o para recobrar decoro ante si propios, los hombres pagados dan, de una sacudida de su espalda, en tierra con los pagadores.

Así, cuando la maldad reina entre los hombres, la virtud tiene siempre hogares encendidos... "La virtud es un hada benéfica: ilumina los corazones por donde pasa: da a la mente las fuerzas del genio".

Habrá una revolución ética y ecológica o no habrá mundo. Junto al desaliento instaurado aumenta también la lumbre y la energía de la prodigiosa labor de centenares de miles de organizaciones y seres singulares que no han renunciado a un sentido elemental del decoro y la dignidad y proponen desde su obrar cotidiano, y entre múltiples resquicios, el cuidado de la vida y no malograrla aún más, proponen formas de vivir enraizadas en la dignidad y el afecto, y no en el odio y la devastadora indiferencia.

Hay que darse cuenta y admirar y apoyar el quehacer de millares de mujeres -sobre todo mujeres- y de hombres que no pueden tener paz mientras la paz genuina -y no el remedo pacificador con el que ahora se pretende birlar la fatiga del odio y la muerte, conservando indemnes las estructuras del odio y la muerte- no sea patrimonio de todos. Hay que descubrir y reavivarse en la tenacidad inverosímil de seres que han consagrado su vida, o la arriesgan, o la ofrendaron, para que la verdad no nos fuese desconocida, ni desconociésemos el significado inefable del vivir en libertad -que es lo mismo que batallar por ella- y no redujésemos el fugaz trasegar por la tierra a la experiencia sórdida de sobrevivir sometidos y silenciados por la nuda fuerza, la atmósfera corrupta, la artimaña infame y el brutal instinto. Todas esas labores de reexistencia reunidas, de coinspiración, decimos, conforman las "columnas del amor sin tregua" de las que hablase Martí, las que sostienen y comunican la prefiguración de otro porvenir posible en esta esquina decisiva de nuestra América que incontenible, emerge.

\section{Referencias}

Bueno, S. \& De la Torriente, P. (s.f.). José Martí y su periódico Patria. S.1.: Puvill Libros.

Díaz, A. (1997). Colombia-Estados Unidos. Bogotá: Planeta.

Fernández, R. \& Rodríguez, P. (2003). José Martí en los Estados Unidos. Periodismo de 1881 a 1892. S.1.: Edición Crítica. 